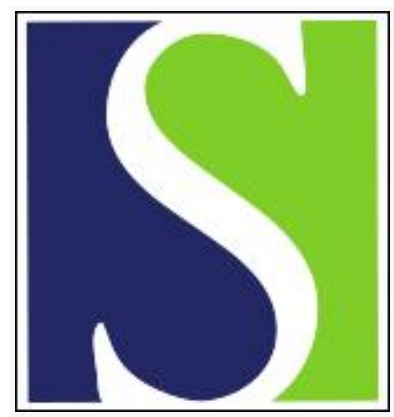

Scand J Work Environ Health 2017;43(2):127-135

https://doi.org/10.5271/sjweh.3614

Published online: 14 Dec 2016, Issue date: 01 Mar 2017

Shift workers have similar leisure-time physical activity levels as day workers but are more sedentary at work

by Hulsegge G, Gupta N, Holtermann A, Jørgensen MB, Proper KI, van $\operatorname{der}$ Beek AJ

In a blue-collar population, shift workers had similar leisure-time physical activity patterns as day workers, but shift workers were more sedentary and less physically active during working hours in comparison with day workers. This indicates that preventive initiatives for this high-risk group should focus not only on lifestyle factors but also on sedentary time during work.

Affiliation: Department of Public \& Occupational Health, EMGO+ Institute for Health \& Care Research, VU University Medical Center, Van der Boechorststraat 7, Postbus 7047, 1007 MB Amsterdam, The Netherlands. g.hulsegge@vumc.nl

Refers to the following texts of the Journal: 2010;36(2):96-108 2011;37(1):6-29 2012;38(6):590-599

The following articles refer to this text: 2018;44(3):265-273;

2018;44(3):225-228; 2020;46(3):293-301

Key terms: 24/7 society; day worker; exposure variation analysis; irregular working hour; leisure-time physical activity; night work; occupational health; physical activity; sedentary; sedentary behavior; shift work; shift worker

This article in PubMed: www.ncbi.nlm.nih.gov/pubmed/27973676

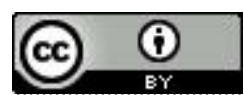




\title{
Shift workers have similar leisure-time physical activity levels as day workers but are more sedentary at work
}

\author{
by Gerben Hulsegge, PhD, ${ }^{1}$ Nidhi Gupta, PhD, ${ }^{2}$ Andreas Holtermann, PhD, ${ }^{2}$ Marie Birk Jørgensen, PhD, ${ }^{2}$ \\ Karin I Proper, PhD, ${ }^{1,3}$ Allard J van der Beek, PhD ${ }^{1}$
}

\begin{abstract}
Hulsegge G, Gupta N, Holtermann A, Jørgensen MB, Proper KI, van der Beek AJ. Shift workers have similar leisure-time physical activity levels as day workers but are more sedentary at work. Scand $\mathrm{J}$ Work Environ Health. 2017;43(2):127-135. doi:10.5271/sjweh.3614
\end{abstract}

Objective Physical inactivity has been hypothesized as an underlying factor for the association between shift work and adverse health outcomes. We compared leisure-time and occupational physical activity and sedentary behavior between day, night, and non-night shift workers.

Methods We identified 612 day workers, 139 night shift workers and 61 non-night shift workers aged 18-65 years (54\% men) in two Danish studies: the New method for Objective Measurements of physical Activity in Daily living (NOMAD) and the Danish Physical ACTivity cohort with Objective measurements (DPhacto) between 2011-2013. Sedentary behavior, light, and moderate-to-vigorous physical activity were measured using an accelerometer. Physical activity was expressed as percentage of leisure and work time spent in each activity. Linear regression analyses were used to test differences in physical activity and sedentary behavior between day, night, and non-night shift workers.

Results No differences in leisure-time sedentary behavior and physical activity were observed between day and shift workers $(\mathrm{P}>0.05)$. Non-night shift workers spent $7.2 \%[95 \%$ confidence interval $(95 \% \mathrm{CI}) 2.3-12.1)$ more time in occupational sedentary behavior than day workers and 5.9\% (95\% CI -10.1- -1.7) and $1.9 \%(95 \%$ CI -3.7- -0.2) less time in occupational light and moderate-to-vigorous physical activity, respectively. Compared to day workers, night shift workers spent $4.3 \%(95 \% \mathrm{CI} 2.4-6.1)$ more time at work in uninterrupted sedentary periods of $\geq 30$ minutes.

Conclusions Shift workers had similar leisure-time physical activity patterns as day workers, but were more sedentary at work. Future research should elucidate whether occupational physical inactivity and sedentary behavior contributes to shift work-related adverse health effects.

Key terms exposure variation analysis; irregular working hour; night work; sedentary behavior; shift work; occupational health; $24 / 7$ society.

Almost one in five of all employees in Europe and the USA work in rotating shifts or during the night $(1,2)$. Due to increasing economic and social demands, shift work is currently an inherent part of modern society. However, accumulating evidence indicates that shift work imposes an increased risk for metabolic disturbances, such as alterations in body weight, glycaemia and lipids (3-5), and several chronic diseases, such as breast cancer, type II diabetes, and cardiovascular disease (6-9).
To alleviate these adverse health effects of shift work, there is a need for insight into the mechanisms underlying this relationship. To date, the causal mechanisms linking shift work and health outcomes are not well understood, but they appear to be multifactorial. Lifestyle behaviors, such as physical inactivity, have been hypothesized but so far untested as one of the underlying mechanisms of adverse health effects of shift work (10). Therefore, it is important to understand differences in physical activity patterns between day and shift workers.

1 Department of Public \& Occupational Health, EMGO+ Institute for Health \& Care Research, VU University Medical Center, Amsterdam, The Netherlands.

2 National Research Centre for the Working Environment, Copenhagen, Denmark.

3 Centre for Nutrition, Prevention and Health Services, National Institute for Public Health and the Environment, Bilthoven, The Netherlands.

Correspondence to: Gerben Hulsegge, Department of Public \& Occupational Health, EMGO+ Institute for Health \& Care Research, VU University Medical Center, Van der Boechorststraat 7, Postbus 7047, 1007 MB Amsterdam, The Netherlands. [E-mail: g.hulsegge@vumc.nl]. 
The findings of previous studies on the relation between shift work and physical activity were mixed, and thus inconclusive. Some studies observed that shift workers were less physically active than day workers (11-13). It has been suggested that this may be because shift workers are more fatigued and have less time to be physically active or are unable to participate in organized sport activities than day workers $(14,15)$. In contrast, other studies observed no difference between day and shift workers (16-19) or observed that shift workers were more physically active $(20,21)$. These studies $(12,13,16-20)$ on shift work and physical activity often lack adjustment for relevant confounders, such as age and gender, and have mainly relied on self-reported physical activity. Self-reports are prone to bias and less reliable than objective methods for assessing physical activity (22-24). Moreover, self-reports do not provide activity patterns in detail, such as time spent in different durations of sitting, standing, and walking (25). In addition, most previous studies did not describe occupational physical activity $(12,18,19,21)$ or distinguish between occupational and leisure-time physical activity among shift workers (11), while shift work may influence occupational physical activity in a different way than leisure-time physical activity (26). For example, time constraints to participate in organized sport activities may decrease leisuretime physical activity, whereas different work tasks between day work and night shifts may be related to different occupational physical activity patterns (14, 15). Thus, detailed information about overall and specified physical activity behaviors (eg, duration and intensity of activity) of shift workers in comparison with day workers is currently lacking. In addition, there is increasing attention for sedentary behavior as an independent (ie, independent from physical activity) risk factor for metabolic disturbances and chronic diseases (27). Knowledge about sedentary behavior across shift work groups is therefore also of importance and has hardly been studied yet.

To evaluate differences in sedentary behavior and physical activity between day and shift workers, it is important to comprehensively capture the complex pattern of sedentary behavior and physical activity using objective measurement instruments. For this purpose, exposure variation analysis has recently been proposed as it includes all important dimensions of physical activity while reducing its complexity (25).

The aim of this study was to compare patterns of objectively measured leisure-time and occupational physical activity and sedentary behavior between day and shift workers. We hypothesized that shift workers have lower leisure-time and occupational physical activity and higher sedentary levels than day workers.

\section{Methods}

\section{Population}

We used data from the two Danish studies: the New method for Objective Measurements of physical Activity in Daily living (NOMAD) (28) and the Danish Physical ACTivity cohort with Objective measurements (DPhacto) (29). In the NOMAD study, 391 blue collar workers aged $18-65$ years who worked $\geq 20$ hours/week were invited to participate. Workers were primarily recruited through contact with trade unions or safety representatives between October 2011 and April 2012. In the DPhacto cohort, 2107 blue-collar workers aged 18-68 years were invited to participate from 15 Danish workplaces between spring 2012 and spring 2013. Details of the study designs of NOMAD and DPhacto have been described elsewhere $(28,29)$. Exclusion criteria were pregnancy and skin allergy to adhesive tape, white-collar workers, and jobs without shift work. All workers gave informed consent and the Ethics Committee for the Capital Region of Denmark approved the study (journal numbers H-2-2011-047 and H-2-2012-011).

\section{Shift work}

In both cohort studies, workers were asked the following question: "Which time of the day do you usually work in your main occupation?". Response options in the NOMAD study were "fixed day work", "fixed evening work (mostly between 15.00-24.00 hours)", "fixed night work (mostly between 24.00-05.00 hours)", "varying working hours with night shifts", "varying working hours without night shifts", and "other". Response options in the DPhacto study were "fixed day work", "night or varying working hours with night shifts", and "other". In the present study, we divided the workers in the following three groups: (i) day workers: workers with fixed day work; (ii) night shift workers: those with fixed night shifts or varying working hours with night shifts; and (iii) non-night shift workers: all others, including fixed evening workers.

\section{Physical activity}

Physical activity was measured for approximately four successive days using the Actigraph GT3X accelerometer fixed halfway between crista iliac and patella at the medial front of the right thigh, as described previously $(30,31)$. Most of the measurements within one company were taken over consecutive days in one week. The workers were allowed to remove the accelerometer if it caused any kind of discomfort, such as itching or disturbed sleep. They were also instructed to perform a reference measurement in a standing position for 15 
seconds every day, and to complete a short diary including the time of the reference measurement and non-wear time, working period, and time in bed.

Stored data of the Actigraph was downloaded using the manufacturer's program Actilife Software version 5.5, and was further analyzed using the custom-made MATLAB program (Acti4, The National Research Centre for the Working Environment, Copenhagen, Denmark and BAuA, Berlin, Germany). This program estimates the type, duration, and variation of physical activities and body postures with a sensitivity of $98 \%$ and specificity of $93 \%$ (31). The following physical activity types were identified from the accelerometer outputs using the individual's reference measurement and algorithms shown elsewhere: sedentary behavior, standing, slow and fast walking, cycling, running, and stair climbing (31).

Consistent with previous work $(28,32,33)$, each leisure- and working-time interval on working days had to contain $\geq 4$ hours/day of accelerometer wear-time or $75 \%$ of the average wear-time across days for the individual. Working time was defined as the self-reported hours spent at the primary occupation and leisure time as the remaining hours. Leisure-time intervals on non-working days were included if accelerometers were worn for $\geq 10$ hours/day or $\geq 75 \%$ of the average time across days when accelerometers were worn (34). Periods of sleep, nonwear, and periods not coded in the diary were excluded from the analyses.

Intensity was categorized into sedentary behavior (lying/sitting), light (stand/slow walking), and moderate-to-vigorous (fast walking/running/cycling). Exposure variation analysis matrices were used that combine simultaneously two core dimensions of physical activity exposure: intensity and duration $(25,35)$. We identified uninterrupted periods of different durations (ie, $<1,1-5$, $5-10,10-30,30-60$, and $>60$ minutes) spent at a certain intensity of physical activity $(25,33)$. The accumulated time spent in each of these duration categories was calculated and expressed as percentage of total time in each activity (35). We did this separately for physical activity during leisure and working time. In accordance with physical activity recommendations $(36,37)$, we also constructed the variable "prolonged sedentary behavior", determined as the time in uninterrupted sedentary periods of $\geq 30$ minutes.

\section{Covariates}

Workers completed a questionnaire including questions on demographics, work-related factors, and lifestyle. Detailed procedures have been described previously (28, 29). Occupational sector was categorized into cleaning, manufacturing, transportation, assembling, healthcare, and garbage collection. Manufacturing jobs included work in the food and metal industry. Manufacturing workers mostly did assembly tasks that included highly repetitive work (ie, short cycle times) and/or assembling an entire product (ie, long cycle times). Job seniority (years) was determined by asking for how long they had the kind of occupation they currently have. We dichotomized smoking into current and non-smoker (28). The frequency of fruit and vegetable intake was categorized into every day and 0-6 times/week. Body weight was objectively measured to the nearest $0.1 \mathrm{~kg}$ and body height to the nearest $\mathrm{cm}$. Body mass index (BMI) was calculated by dividing weight by height squared $\left(\mathrm{kg} / \mathrm{m}^{2}\right)$.

\section{Data analysis}

The two-sample $t$-test and chi-square test were used to assess differences in baseline variables between day and shift workers. The differences in percentage time spent in different physical activity types were described for day and shift workers, separately for leisure and working time. Leisure-time physical activity during week and weekend days were combined in the analyses because, in relation to shift work status, no differences were observed between physical activity on weekdays and weekend days. Differences between day and shift workers in sedentary behavior, light, and moderate-tovigorous physical activity were analyzed using linear regression analyses. All analyses were adjusted for age, gender, occupational sector, working hours/week, job seniority, smoking status, and fruits and vegetables intake. Occupational physical activity has been found to be associated with leisure-time physical activity (38). Since activities that each job requires may differ, physical activity during leisure time was additionally adjusted for the percentage of time spent in occupational moderate-to-vigorous-intensity physical activity. Finally, for more detailed insight into differences in physical activity and sedentary behavior between day and shift workers, the exposure variation analysis matrices were used. In doing so, the percentage of total time in each uninterrupted period of the six different durations for light and moderate-to-vigorous physical activity and sedentary behavior were calculated.

\section{Results}

\section{Population}

Of the 1422 workers, we excluded 253 white-collar workers, 53 individuals who worked in an occupational sector in which nobody did shift work, 221 individuals without valid accelerometer data, and 83 individuals with missing values on shift work status or covariates (figure 1). Non-night shift workers who reported to have 


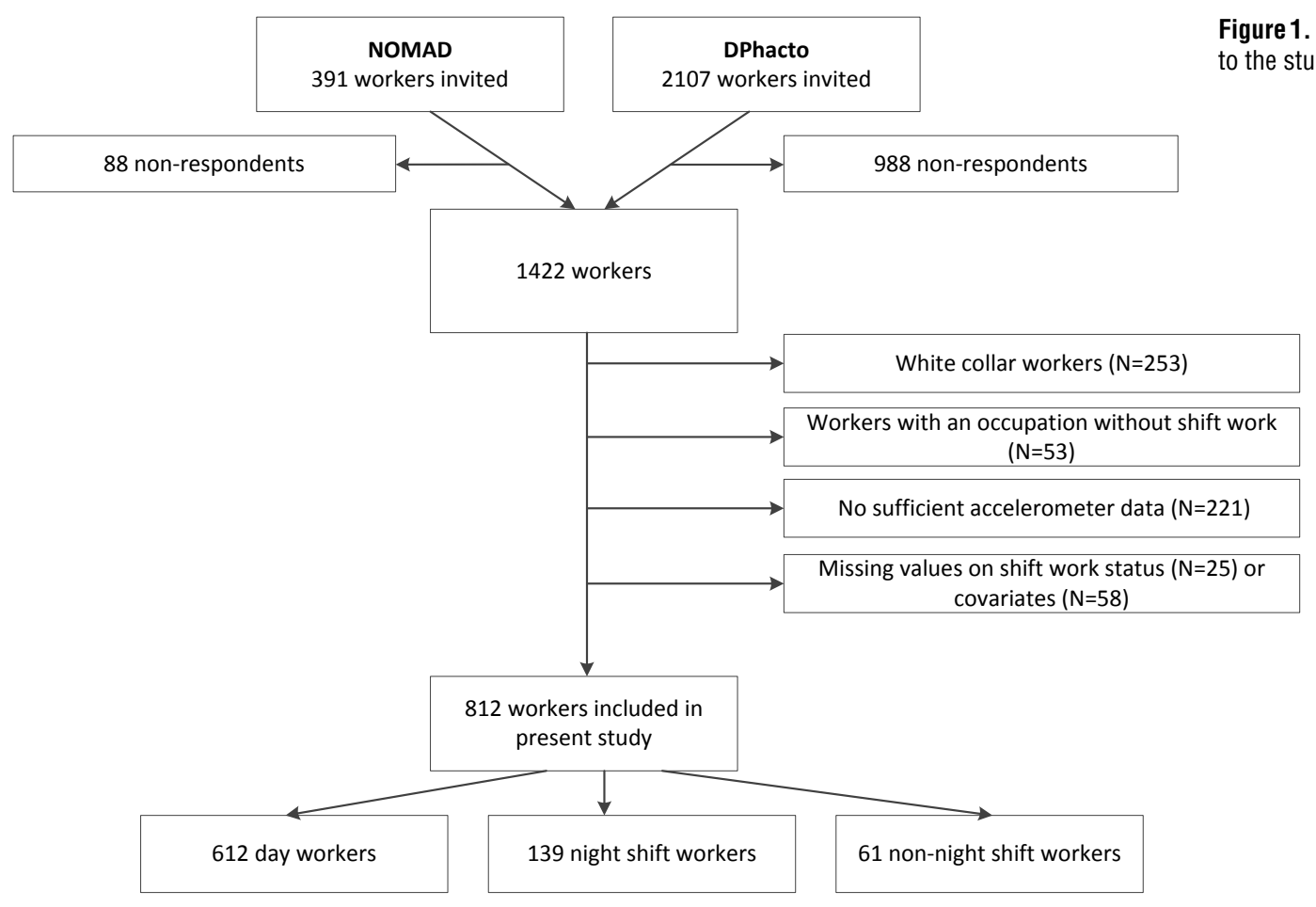

done a night shift in their diary during the days they wore an accelerometer were also considered night shift workers $(\mathrm{N}=6)$. This led to a study population of 612 day workers, 139 night shift workers, and 61 non-night shift workers.

The mean age was 45.0 [standard deviation (SD) $10.0]$ years and $54 \%$ of the workers were men. Compared to day workers, night shift workers were more often men and smokers, ate fruits and vegetables on a daily basis less often, and worked in transportation more often. Night shift workers did not work in healthcare or as garbage collectors. Non-night shift workers were more often smokers and worked in manufacturing less often than day workers (table 1).

\section{Physical activity patterns}

In total, 50911 waking hours and 3519 days of physical activity were included in the analyses. Workers wore an accelerometer on average for 3.3 (SD 0.9) days on working days and for 1.9 (SD 0.8) days on non-working days (table 1). The workers spent almost two-thirds of their time during leisure and about one-third during work in sedentary behavior (table 2). Workers stood and walked slowly approximately $30 \%$ of the time during leisure and about $50 \%$ during work. Fast walking covered most of the remainder of the waking time (6.3-14.7\%), and other activities (ie, stair climbing, running, and cycling) were done about $1 \%$ of the measured time.

During leisure time on working and non-working days, no clear differences in time spent in different physical activities were observed between day and shift workers (table 2). The percentage time spent in occupational sedentary behavior was numerically higher in the shift work than day work group, while the percentage time spent walking at work was numerically lower in the shift work groups. Results of the univariable and multivariable-adjusted analyses, showed no differences in percentage time spent in leisure-time sedentary behavior, light, and moderate-to-vigorous physical activity between day, night shift and non-night shift workers $(\mathrm{P}>0.05)$ (table 3). At work, non-night shift workers spent statistically significantly $[7.2 \%, 95 \%$ confidence interval $(95 \%$ CI) 2.3-12.1] more time in sedentary behavior than day workers, while they spent $5.9 \%$ (95\% CI -10.1- -1.7) and $1.9 \%$ (95\% CI -3.7- - 0.2$)$ less time in light and moderateto-vigorous physical activity, respectively. No statistically significant differences in overall occupational sedentary behavior and physical activity were observed between day and night shift workers $(\mathrm{P}>0.05)$.

Exposure variation analysis confirmed the absence of differences in leisure-time sedentary behavior and physical activity between day and shift workers (table 4). At work, both night (11.1\%) and non-night (8.4\%) shift workers spent more time in uninterrupted sedentary periods of $30-60$ and $\geq 60$ minutes than day workers (4.9\%). In multivariable-adjusted analyses, night shift workers spent statistically significantly $(4.3 \%, 95 \% \mathrm{CI}$ 2.4-6.1) more time in prolonged ( $\geq 30$ minutes) occupational sedentary behavior than day workers. 
Table 1. Baseline characteristics by shift work status. [SD=standard deviation

\begin{tabular}{|c|c|c|c|c|c|c|c|c|c|c|c|c|}
\hline & \multicolumn{4}{|c|}{ Day workers (N=612) } & \multicolumn{4}{|c|}{ Night shift workers ( $\mathrm{N}=139)$} & \multicolumn{4}{|c|}{ Non-night shift workers (N=61) } \\
\hline & $\mathrm{N}$ & $\%$ & Mean & SD & $\mathrm{N}$ & $\%$ & Mean & SD & $\mathrm{N}$ & $\%$ & Mean & SD \\
\hline \multicolumn{13}{|l|}{ Demographics } \\
\hline Age (years) & & & 45.5 & 10.0 & & & 43.5 & 9.9 & & & 44.0 & 9.2 \\
\hline Gender (male) & 308 & 50 & & & 100 & $72^{\text {a }}$ & & & 27 & 44 & & \\
\hline \multicolumn{13}{|l|}{ Occupational } \\
\hline Working hours/week & & & 37 & 6 & & & 40 & 9 & & & 37 & 6 \\
\hline Seniority job (years) & & & 13 & 10 & & & 12 & $1^{\mathrm{a}}$ & & & 11 & 10 \\
\hline \multicolumn{13}{|l|}{ Occupational sector } \\
\hline Cleaning & 126 & 21 & & & 7 & 5 & & & 18 & 30 & & \\
\hline Manufacturing & 398 & 65 & & & 100 & 70 & & & 29 & $48 \mathrm{c}$ & & \\
\hline Transportation & 34 & 6 & & & 25 & $18^{\mathrm{a}}$ & & & 6 & 10 & & \\
\hline Assembling & 18 & 3 & & & 7 & 5 & & & 4 & 7 & & \\
\hline Health care & 10 & 2 & & & 0 & 0 & & & 3 & 5 & & \\
\hline Garbage collectors & 26 & 4 & & & 0 & $0^{a}$ & & & 1 & 2 & & \\
\hline Night shift during measurement day ${ }^{b}$ & & & & & 79 & 57 & & & & & & \\
\hline Non-night irregular shift during measurement day ${ }^{c}$ & & & & & 109 & 78 & & & 50 & 82 & & \\
\hline Any non-day time shift during measurement day & & & & & 117 & 84 & & & 50 & 82 & & \\
\hline \multicolumn{13}{|l|}{ Health and lifestyle } \\
\hline Smoker & 182 & 30 & & & 55 & $40^{\mathrm{a}}$ & & & 29 & $48 \mathrm{c}$ & & \\
\hline Vegetables (daily) & 252 & 41 & & & 44 & $32^{\text {a }}$ & & & 23 & 38 & & \\
\hline Fruits (daily) & 327 & 53 & & & 54 & 39 a & & & 25 & 41 & & \\
\hline Body mass index $\left(\mathrm{kg} / \mathrm{m}^{2}\right)$ & & & 27.4 & 4.9 & & & 26.9 & 4.5 & & & 27.1 & 5.4 \\
\hline \multicolumn{13}{|l|}{ Wear-time accelerometer } \\
\hline Measured working days with leisure-time & & & 3.0 & 1.0 & & & 2.7 & $1.1^{\mathrm{a}}$ & & & 2.6 & $1.0^{\mathrm{a}}$ \\
\hline Measured non-working days & & & 1.9 & 0.7 & & & 1.8 & 0.9 & & & 1.9 & 1.2 \\
\hline Measured working days with work time & & & 2.9 & 0.9 & & & 3.0 & 1.2 & & & 3.1 & $0.9 \mathrm{a}$ \\
\hline Average wear-time leisure working day (hours/day) & & & 8.8 & 1.9 & & & 8.5 & $2.1^{\mathrm{a}}$ & & & 8.5 & $1.7^{\mathrm{a}}$ \\
\hline Average measured time non-working days (hours/day) & & & 14.9 & 1.5 & & & 14.9 & 1.8 & & & 15.1 & 2.1 \\
\hline Average wear-time work (hours/day) & & & 7.4 & 1.7 & & & 8.3 & $1.5^{\mathrm{a}}$ & & & 7.8 & 1.2 \\
\hline
\end{tabular}

${ }^{a}$ Statistically significant difference $(\mathrm{P}<0.05)$ tested with the two-sample t-test and chi-square test between night shift workers, non-night shift workers and day workers (reference).

b Worked $\geq 3$ hours between $00.00-05.00$ hours during one of the days the workers wore an accelerometer.

c Worked in an evening (start after 16.00 and stop between 21.00-23.59 hours) or morning (start between 04.00-06.00 hours) shift during one of the days the worker wore an accelerometer.

Table 2. Percentage time spent in different types of physical activity during leisure time and at work. [SD=standard deviation.]

\begin{tabular}{|c|c|c|c|c|c|c|c|c|c|c|c|c|}
\hline & \multicolumn{6}{|c|}{ Leisure time on working and non-working days } & \multicolumn{6}{|c|}{ Work time } \\
\hline & \multicolumn{2}{|c|}{$\begin{array}{l}\text { Day worker } \\
(\mathrm{N}=610)\end{array}$} & \multicolumn{2}{|c|}{$\begin{array}{c}\text { Night shift } \\
\text { worker }(N=139)\end{array}$} & \multicolumn{2}{|c|}{$\begin{array}{l}\text { Non-night shift } \\
\text { worker }(\mathrm{N}=61)\end{array}$} & \multicolumn{2}{|c|}{$\begin{array}{l}\text { Day worker } \\
(\mathrm{N}=602)\end{array}$} & \multicolumn{2}{|c|}{$\begin{array}{c}\text { Night shift } \\
\text { worker }(\mathrm{N}=135)\end{array}$} & \multicolumn{2}{|c|}{$\begin{array}{l}\text { Non-night shift } \\
\text { worker }(\mathrm{N}=57)\end{array}$} \\
\hline & $\%$ & SD & $\%$ & SD & $\%$ & SD & $\%$ & SD & $\%$ & SD & $\%$ & SD \\
\hline Sedentary & 61.1 & 14.0 & 62.4 & 14.3 & 60.9 & 12.9 & 30.8 & 18.7 & 36.2 & 23.1 & 39.8 & 22.4 \\
\hline Standing & 26.3 & 9.4 & 24.8 & 9.3 & 27.1 & 9.2 & 49.0 & 17.1 & 45.0 & 19.5 & 42.0 & 20.3 \\
\hline Slow walking & 2.1 & 1.1 & 2.3 & 1.5 & 2.0 & 1.1 & 3.8 & 2.5 & 4.1 & 3.0 & 2.8 & 1.8 \\
\hline Fast walking & 6.7 & 2.9 & 6.3 & 2.9 & 6.8 & 2.7 & 14.7 & 7.1 & 13.6 & 5.4 & 12.8 & 6.2 \\
\hline Stair climbing & 0.5 & 0.5 & 0.4 & 0.4 & 0.5 & 0.5 & 0.8 & 0.9 & 0.8 & 0.7 & 0.8 & 0.7 \\
\hline Running & 0.21 & 0.87 & 0.29 & 0.80 & 0.09 & 0.30 & 0.09 & 0.56 & 0.04 & 0.04 & 0.04 & 0.08 \\
\hline Cycling & 0.50 & 1.30 & 0.57 & 1.45 & 1.05 & 2.06 & 0.06 & 0.30 & 0.07 & 0.21 & 0.17 & 0.48 \\
\hline
\end{tabular}

\section{Discussion}

In this blue-collar population, night and non-night shift workers had similar objectively measured leisure-time physical activity patterns compared to day workers. At work, non-night shift workers spent more time in sedentary behavior and less time in light and moderateto-vigorous physical activity than day workers. In comparison with day workers, both night and non-night shift workers spent more time in prolonged periods of $\geq 30$ minutes of sedentary behavior at work.

Most previous studies observed no differences in self-reported moderate and moderate-to-vigorous physical activity during leisure time between day and shift workers $(16-18,39,40)$. We extended previous findings to leisure-time sedentary behavior by investigating physical activity patterns in much more detail using objective data, but still found no differences between day and shift workers. In contrast, one study, which also used objectively measured physical activity, observed that rotating shift workers engage in less sedentary 
Table 3. Differences in the percentage time spent in a certain intensity of physical activity between night shift workers ( $N=139)$, non-night shift workers $(\mathrm{N}=61)$ and day workers $(\mathrm{N}=612)$ (reference). Significant associations are shown in bold. [95\% $\mathrm{Cl}=95 \%$ confidence interval.]

\begin{tabular}{|c|c|c|c|c|c|c|c|c|c|c|c|c|c|c|c|}
\hline & \multicolumn{5}{|c|}{ Sedentary behavior } & \multicolumn{5}{|c|}{ Light physical activity } & \multicolumn{5}{|c|}{ Moderate-to-vigorous physical activity } \\
\hline & \multirow[t]{2}{*}{$\begin{array}{l}\text { Day } \\
\text { workers }\end{array}$} & \multicolumn{2}{|c|}{$\begin{array}{l}\text { Night shift } \\
\text { workers }\end{array}$} & \multicolumn{2}{|c|}{$\begin{array}{l}\text { Non-night } \\
\text { shift workers }\end{array}$} & \multirow[t]{2}{*}{$\begin{array}{l}\text { Day } \\
\text { workers }\end{array}$} & \multicolumn{2}{|c|}{$\begin{array}{c}\text { Night shift } \\
\text { workers }\end{array}$} & \multicolumn{2}{|c|}{$\begin{array}{l}\text { Non-night } \\
\text { shift workers }\end{array}$} & \multirow[t]{2}{*}{$\begin{array}{c}\text { Day } \\
\text { workers }\end{array}$} & \multicolumn{2}{|c|}{$\begin{array}{l}\text { Night shift } \\
\text { workers }\end{array}$} & \multicolumn{2}{|c|}{$\begin{array}{c}\text { Non-night } \\
\text { shift workers }\end{array}$} \\
\hline & & B & $95 \% \mathrm{Cl}$ & B & $95 \% \mathrm{Cl}$ & & B & $95 \% \mathrm{Cl}$ & B & $95 \% \mathrm{Cl}$ & & $B$ & $95 \% \mathrm{Cl}$ & B & $95 \% \mathrm{Cl}$ \\
\hline \multicolumn{16}{|l|}{ Leisure time } \\
\hline Model 1 a & ref & 0.7 & $-1.8-3.3$ & 0.2 & $-3.5-3.8$ & 8 ref & -0.5 & $-2.3-1.3$ & -1.5 & $-4.9-1.9$ & ref & -0.1 & $-0.8-0.3$ & 0.5 & $-0.5-1.4$ \\
\hline Model 2 b & ref & 0.3 & $-2.4-2.9$ & -0.05 & $-3.7-3.6$ & 6 ref & -0.4 & $-2.2-1.5$ & 0.4 & $-2.2-3.0$ & ref & 0.02 & $-0.7-0.7$ & 0.4 & $-0.5-1.4$ \\
\hline Model $3^{c}$ & ref & -0.02 & $-2.7-2.7$ & -0.2 & $-4.0-3.6$ & 6 ref & -0.1 & $-2.0-1.7$ & 0.2 & $-2.4-2.9$ & ref & 0.1 & $-0.6-0.8$ & 1.0 & $0.1-2.0$ \\
\hline \multicolumn{16}{|l|}{ Work time } \\
\hline Model $1^{\text {a }}$ & ref & 4.0 & $0.3-7.7$ & 9.6 & $4.2-14.9$ & 9 ref & -2.1 & $-5.6-1.3$ & -8.4 & $-13.4--3.4$ & ref & -1.3 & $-2.7-0.1$ & -1.9 & $-3.9-0.1$ \\
\hline Model 2 b & ref & 0.5 & $-2.9-4.0$ & 7.2 & $2.3-12.0$ & D ref & 0.1 & $-2.9-3.1$ & -5.9 & $-10.0--1.7$ & ref & 0.1 & $-1.1-1.3$ & -2.0 & $-3.7--0.2$ \\
\hline Model $3^{c}$ & ref & 0.6 & $-2.8-4.1$ & 7.2 & 2.3-12.1 & 1 ref & -0.1 & $-3.1-3.0$ & -5.9 & $-10.1--1.7$ & ref & 0.2 & $-1.1-1.4$ & -1.9 & $-3.7--0.2$ \\
\hline
\end{tabular}

a Presented as regression coefficients $(95 \% \mathrm{Cl})$ of the difference in percentage time spent in each physical activity obtained by linear regression analyses adjusted for age and gender.

b Model 1 and additionally adjusted for occupational sector, working hours, and seniority job.

c Model 2 and additionally adjusted for fruits, vegetables, smoking and body mass index. Leisure-time physical activity was additionally adjusted for moderate-to-vigorous intensity physical activity at work.

Table 4. Percentage time spent in sedentary behavior, light, and moderate-to-vigorous intensity physical activity in uninterrupted periods (ranging from $<1->60$ minutes) for day ( $N=612)$, night shift workers $(\mathrm{N}=139)$, and non-night shift workers $(\mathrm{N}=61)$.

\begin{tabular}{|c|c|c|c|c|c|c|c|c|c|}
\hline & \multicolumn{3}{|c|}{ Sedentary behavior } & \multicolumn{3}{|c|}{ Light physical activity } & \multicolumn{3}{|c|}{ Moderate-to-vigorous physical activity } \\
\hline & Day workers & $\begin{array}{l}\text { Night shift } \\
\text { workers }\end{array}$ & $\begin{array}{c}\text { Non-night } \\
\text { shift workers }\end{array}$ & Day workers & $\begin{array}{l}\text { Night shift } \\
\text { workers }\end{array}$ & $\begin{array}{c}\text { Non-night } \\
\text { shift workers }\end{array}$ & Day workers & $\begin{array}{l}\text { Night shift } \\
\text { workers }\end{array}$ & $\begin{array}{c}\text { Non-night } \\
\text { shift workers }\end{array}$ \\
\hline & $\%$ & $\%$ & $\%$ & $\%$ & $\%$ & $\%$ & $\%$ & $\%$ & $\%$ \\
\hline \multicolumn{10}{|c|}{ Leisure time (minutes) } \\
\hline$<1$ & 1.3 & 1.3 & 1.3 & 10.2 & 9.9 & 10.4 & 5.9 & 5.8 & 6.0 \\
\hline $1-5$ & 4.8 & 4.8 & 4.8 & 12.5 & 11.8 & 12.9 & 1.3 & 1.2 & 1.7 \\
\hline $5-10$ & 6.1 & 6.1 & 6.6 & 3.6 & 3.3 & 3.7 & 0.4 & 0.4 & 0.5 \\
\hline $10-30$ & 21.3 & 21.4 & 17.1 & 3.1 & 3.0 & 3.1 & 0.4 & 0.3 & 0.3 \\
\hline $30-60$ & 14.0 & 13.9 & 15.9 & 0.13 & 0.12 & 0.12 & 0.10 & 0.06 & 0.06 \\
\hline$\geq 60$ & 15.0 & 15.0 & 15.2 & 0.02 & 0.05 & 0.04 & 0.003 & 0.040 & 0.000 \\
\hline \multicolumn{10}{|c|}{ Work time (minutes) } \\
\hline$<1$ & 1.9 & 1.6 & 1.8 & 19.1 & 24.6 & 18.5 & 14.0 & 13.0 & 12.5 \\
\hline $1-5$ & 5.5 & 5.0 & 7.0 & 21.7 & 19.1 & 17.5 & 1.8 & 1.7 & 1.4 \\
\hline $5-10$ & 5.5 & 4.9 & 7.7 & 5.5 & 3.6 & 4.8 & 0.1 & 0.04 & 0.1 \\
\hline $10-30$ & 13.1 & 13.4 & 15.0 & 4.4 & 2.2 & 5.0 & 0.0 & 0.0 & 0.0 \\
\hline $30-60$ & 3.9 & 4.9 & 5.4 & 0.1 & 0.1 & 0.2 & 0.0 & 0.0 & 0.0 \\
\hline$\geq 60$ & 1.0 & 6.2 & 3.0 & 0.04 & 0.0 & 0.0 & 0.0 & 0.0 & 0.0 \\
\hline
\end{tabular}

behavior and more total light-intensity physical activity without distinguishing between leisure-time and occupational activities (11). Our findings imply differences between day and shift workers during working time, but not during leisure time. In addition, no studies have, to our knowledge, investigated objectively measured physical activity during leisure time in relation to shift and night work. A recent study showed no difference in self-reported leisure-time vigorous physical activity or sport activities between day and shift workers (21). In contrast, afternoon workers and female night shift workers have been shown to participate less in vigorous physical activity than day workers $(16,18)$. Although these two studies suggest that some shift workers are less vigorously physically active than day workers, the majority of the studies up to now, including the present, suggest similar leisure-time physical activity patterns among shift and day workers.
In line with our findings, Loprinzi observed that rotating shift workers spent more time, and night shift workers a similar amount of time, in sedentary behavior compared to day workers (11). As described above, our results imply that this is probably only due to increased sedentary behavior among shift workers during working hours. We also showed that shift workers spent more time in prolonged periods of occupational sedentary behavior compared to day workers. The increased sedentary behavior among non-night shift workers in our study was in line with less light- and moderate-intensity physical activity. Reasons for this increased sedentary behavior and decreased light- and moderate-intensity occupational physical activity among shift workers are unknown. It could not be explained by type of occupation, for which we thoroughly controlled. Although speculative, a potential explanation might be that work tasks during irregular shifts are different compared to 
tasks during regular day work. For example, irregular shifts might include more supervisory tasks instead of performing tasks, which give rise to more sedentary behavior. It has also been shown that shift workers are more fatigued and consequently less motivated to work during non-daytime shifts than during day work (26). Hence, another reason may be that tiredness and decreased work motivation during irregular shifts lead to more occupational sedentary behavior. Increased sedentary behavior due to irregular shifts may have health implications since sedentary behavior, especially uninterrupted bouts, are associated with adverse cardiometabolic health outcomes, such as overweight and glycaemia (41). However, it can be hypothesized that it is beneficial for shift workers with physically demanding jobs (eg, manufacturing and cleaning) to be more sedentary at work in order to recover from physically demanding tasks. Although this may be the case for some shift workers, we observed that shift workers spent more time in long uninterrupted periods of sedentary behavior instead of only short recovery periods. Still, before strong conclusions can be drawn on this topic, future studies are needed to confirm the potential link between shift work, occupational sedentary behavior and physical inactivity, and adverse health outcomes. The potentially underlying reasons, such as different work tasks during irregular shifts compared to regular day work, should also be further studied.

\section{Strenths and limitations}

The main strength of the present study is that we used objectively measured physical activity in a homogeneous group of blue-collar workers. Physical activity types in our study were determined using validated software (Acti4) (31). However, the limited information about shift work, in particular frequency of shifts, is a limitation of our study. If shift work changes physical activity patterns, then it is likely that shift workers with many shifts are most affected. However, the frequency of non-daytime shifts (eg, morning or evening shifts) seems high in our shift work groups: $84 \%$ of night and $82 \%$ of non-night shift workers worked in a non-daytime shift during the average accelerometer wearing time of three days. In sensitivity analysis, we also observed that night shift workers who worked $\geq 1$ night (57\%) during the days they wore accelerometers did not have a different physical activity pattern than day workers. Thus, the shift workers in our study probably performed enough irregular shifts to potentially detect differences in physical activity levels compared to day workers. Since work tasks and physical activity in many occupations depend on the time of the day, physical activity may vary across type of shifts (eg, morning, night shift). Due to limited statistical power, we were unable to stratify the results by type of shift. Future research is needed to determine whether our results apply to all type of shifts or whether certain shifts introduce more sedentary behavior than other shifts. Furthermore, our population spent very little time in vigorous physical activities, which makes it difficult to observe differences in vigorous physical activities between day and shift workers. However, this homogeneous population minimizes the issue of residual confounding by occupation and socioeconomic status. Finally, our results are applicable to blue-collar workers, in particular, to cleaners and workers in manufacturing and transportation who formed the greatest part of the population.

In conclusion, blue-collar shift workers had similar leisure-time sedentary behavior and physical activity patterns as day workers. These findings strengthen the conclusions from previous studies $(16-18,39,40)$ that shift work has little or no influence on overall leisuretime sedentary behavior and physical activity. The current evidence thus suggests that leisure-time physical activity does not play a role as underlying mechanism of shift work-related adverse health outcomes. In our study, shift workers, particularly non-night shift workers, spent more time in (prolonged) sedentary behavior and were less physically active at work compared to day workers. This indicates that measures for shift workers should focus on reducing (prolonged periods) of sedentary time during working hours. However, the role of this increased occupational sedentary behavior and physical inactivity among shift workers for health (ie, metabolic disturbances) needs further consideration. Differences in activities during day work and non-daytime shifts should be further investigated as well as the temporal relation between shift work, occupational sedentary behavior and physical inactivity, and adverse health consequences.

\section{Acknowledgements}

This research was funded by the ReVanche Program of the EMGO+ Institute for Health and Care Research of the VU University Medical Center, Amsterdam (grant number: 9729). We would like to thank Jørgen Skotte form the NRCWE for his technical assistance in this study and Anders Ørberg from the NRCWE for his help with data management.

\section{Conflict of interest}

The authors report no conflict of interest. 


\section{References}

1. Costa G. Shift work and occupational medicine: an overview. Occup Med (Lond). 2003;53:83-8. https://doi.org/10.1093/ occmed/kqg045.

2. U.S. Bureau of Labor Statistics, Employment and Wages, 2004 annual averages. Washington; U.S. Available from: http:// www.bls.gov/cew/cewbultn04.htm. [accessed March 2016]

3. Antunes LC, Levandovski R, Dantas G, Caumo W, Hidalgo MP. Obesity and shift work: chronobiological aspects. Nutr Res Rev. 2010;23:155-68. https://doi.org/10.1017/ S0954422410000016.

4. Brum MC, Filho FF, Schnorr CC, Bottega GB, Rodrigues TC. Shift work and its association with metabolic disorders. Diabetol Metab Syndr. 2015;7:45. https://doi.org/10.1186/ s13098-015-0041-4.

5. Proper KI, van de Langenberg D, Rodenburg W, Vermeulen RC, van der Beek AJ, van Steeg H, et al. The Relationship Between Shift Work and Metabolic Risk Factors: A Systematic Review of Longitudinal Studies. Am J Prev Med. 2016;50(50):e147-57. https://doi.org/10.1016/j. amepre.2015.11.013.

6. Gan Y, Yang C, Tong X, Sun H, Cong Y, Yin X, et al. Shift work and diabetes mellitus: a meta-analysis of observational studies. Occup Environ Med. 2015;72:72-8. https://doi. org/10.1136/oemed-2014-102150.

7. Puttonen S, Harma M, Hublin C. Shift work and cardiovascular disease - pathways from circadian stress to morbidity. Scand J Work Environ Health. 2010;36:96-108. https://doi. $\operatorname{org} / 10.5271 /$ sjweh.2894.

8. Vyas MV, Garg AX, Iansavichus AV, Costella J, Donner A, Laugsand LE, et al. Shift work and vascular events: systematic review and meta-analysis. BMJ. 2012;345:e4800. https://doi. org/10.1136/bmj.e4800

9. Wang F, Yeung KL, Chan WC, Kwok CC, Leung SL, Wu C, et al. A meta-analysis on dose-response relationship between night shift work and the risk of breast cancer. Ann Oncol. 2013;24:2724-32. https://doi.org/10.1093/annonc/mdt283.

10. Fritschi L, Glass DC, Heyworth JS, Aronson K, Girschik J, Boyle T, et al. Hypotheses for mechanisms linking shiftwork and cancer. Med Hypotheses. 2011;77:430-6. https://doi. org/10.1016/j.mehy.2011.06.002.

11. Loprinzi PD. The effects of shift work on free-living physical activity and sedentary behavior. Prev Med. 2015;76:43-7. https://doi.org/10.1016/j.ypmed.2015.03.025.

12. Nabe-Nielsen K, Quist HG, Garde AH, Aust B. Shiftwork and changes in health behaviors. J Occup Environ Med. 2011;53:1413-7. https://doi.org/10.1097/ JOM.0b013e31823401f0.

13. Vandelanotte C, Short C, Rockloff M, Di Millia L, Ronan K, Happell B, et al. How do different occupational factors influence total, occupational, and leisure-time physical activity? J Phys Act Health. 2015;12:200-7. https://doi. org/10.1123/jpah.2013-0098.
14. Atkinson G, Davenne D. Relationships between sleep, physical activity and human health. Physiol Behav. 2007;90:229-35. https://doi.org/10.1016/j.physbeh.2006.09.015.

15. Atkinson G, Fullick S, Grindey C, Maclaren D. Exercise, energy balance and the shift worker. Sports Med. 2008;38:67185. https://doi.org/10.2165/00007256-200838080-00005.

16. Ma CC, Burchfiel CM, Fekedulegn D, Andrew ME, Charles LE, Gu JK, et al. Association of shift work with physical activity among police officers: the Buffalo cardio-metabolic occupational police stress study. J Occup Environ Med. 2011;53:1030-6. https://doi.org/10.1097/ JOM.0b013e31822589f9.

17. van Amelsvoort LG, Schouten EG, Kok FJ. Impact of one year of shift work on cardiovascular disease risk factors. J Occup Environ Med. 2004;46:699-706. https://doi.org/10.1097/01. jom.0000131794.83723.45

18. Wang XS, Travis RC, Reeves G, Green J, Allen NE, Key TJ, et al. Characteristics of the Million Women Study participants who have and have not worked at night. Scand J Work Environ Health. 2012;38:590-9. https://doi.org/10.5271/sjweh.3313.

19. Kivimaki M, Kuisma P, Virtanen M, Elovainio M. Does shift work lead to poorer health habits? A comparison between women who had always done shift work with those who had never done shift work. Work Stress.2001;15:3-13. https://doi. org/10.1080/02678370118685.

20. Esquirol Y, Bongard V, Mabile L, Jonnier B, Soulat JM, Perret B. Shift work and metabolic syndrome: respective impacts of job strain, physical activity, and dietary rhythms. Chronobiol Int. 2009;26:544-59. https://doi. org/10.1080/07420520902821176.

21. Loef B, Hulsegge G, Wendel-Vos GC, Verschuren WM, Vermeulen RC, Bakker MF, et al. Non-occupational physical activity levels of shift workers compared with non-shift workers. Occup Environ Med. 2016 [Epub ahead of print]. https://doi.org/10.1136/oemed-2016-103878.

22. Berntsen S, Hageberg R, Aandstad A, Mowinckel P, Anderssen $\mathrm{SA}$, Carlsen KH, et al. Validity of physical activity monitors in adults participating in free-living activities. Br J Sports Med. 2010;44:657-64. https://doi.org/10.1136/bjsm.2008.048868.

23. Kwak L, Proper KI, Hagstromer M, Sjostrom M. The repeatability and validity of questionnaires assessing occupational physical activity--a systematic review. Scand J Work Environ Health. 2011;37:6-29. https://doi.org/10.5271/ sjweh.3085.

24. Lagersted-Olsen J, Korshoj M, Skotte J, Carneiro IG, Sogaard K, Holtermann A. Comparison of objectively measured and self-reported time spent sitting. Int J Sports Med. 2014;35:534-40.

25. Straker L, Campbell A, Mathiassen SE, Abbott RA, Parry S, Davey P. Capturing the pattern of physical activity and sedentary behavior: exposure variation analysis of accelerometer data. J Phys Act Health. 2014;11:614-25. https://doi.org/10.1123/jpah.2012-0105.

26. Ahsberg E, Kecklund G, Akerstedt T, Gamberale F. Shiftwork and different dimensions of fatigue. Int $\mathrm{J}$ Ind 
Ergon. 2000;26:457-65. https://doi.org/10.1016/S01698141(00)00007-X.

27. Edwardson CL, Gorely T, Davies MJ, Gray LJ, Khunti $\mathrm{K}$, Wilmot EG, et al. Association of sedentary behavior with metabolic syndrome: a meta-analysis. PLoS One. 2012;7:e34916. https://doi.org/10.1371/journal. pone. 0034916 .

28. Gupta N, Christiansen CS, Hallman DM, Korshoj M, Carneiro IG, Holtermann A. Is objectively measured sitting time associated with low back pain? A cross-sectional investigation in the NOMAD study. PLoS One. 2015;10:e0121159. https:// doi.org/10.1371/journal.pone.0121159.

29. Jorgensen MB, Korshoj M, Lagersted-Olsen J, Villumsen M, Mortensen OS, Skotte J, et al. Physical activities at work and risk of musculoskeletal pain and its consequences: protocol for a study with objective field measures among blue-collar workers. BMC Musculoskelet Disord. 2013;14:213. https:// doi.org/10.1186/1471-2474-14-213.

30. Korshoj M, Skotte JH, Christiansen CS, Mortensen P, Kristiansen J, Hanisch C, et al. Validity of the Acti4 software using ActiGraph GT3X+accelerometer for recording of arm and upper body inclination in simulated work tasks. Ergonomics. 2014;57:247-53. https://doi.org/10.1080/0014 0139.2013.869358.

31. Skotte J, Korshoj M, Kristiansen J, Hanisch C, Holtermann A. Detection of physical activity types using triaxial accelerometers. J Phys Act Health. 2014;11:76-84. https://doi. org/10.1123/jpah.2011-0347.

32. Hallman DM, Gupta N, Mathiassen SE, Holtermann A. Association between objectively measured sitting time and neck-shoulder pain among blue-collar workers. Int Arch Occup Environ Health. 2015;88:1031-42. https://doi. org/10.1007/s00420-015-1031-4.

33. Hallman DM, Mathiassen SE, Gupta N, Korshoj M, Holtermann A. Differences between work and leisure in temporal patterns of objectively measured physical activity among blue-collar workers. BMC Public Health. 2015;15:976 https://doi.org/10.1186/s12889-015-2339-4.
34. Healy GN, Clark BK, Winkler EA, Gardiner PA, Brown WJ, Matthews CE. Measurement of adults' sedentary time in population-based studies. Am J Prev Med. 2011;41:216-27. https://doi.org/10.1016/j.amepre.2011.05.005.

35. Mathiassen SE, Winkel J. Quantifying variation in physical load using exposure-vs-time data. Ergonomics. 1991;34:145568. https://doi.org/10.1080/00140139108964889.

36. Bull FC. Expert Working Groups: Physical activity guidelines in the U.K.: Review and recommendations. Leicestershire, UK: School of Sport, Exercise, and Health Sciences. Loughborough University; 2010.

37. Tremblay MS, Warburton DE, Janssen I, Paterson DH, Latimer AE, Rhodes RE, et al. New Canadian physical activity guidelines. Appl Physiol Nutr Metab. 2011;36:36-46. https:// doi.org/10.1139/H11-009.

38. Kirk MA, Rhodes RE. Occupation correlates of adults' participation in leisure-time physical activity: a systematic review. Am J Prev Med. 2011;40:476-85. https://doi. org/10.1016/j.amepre.2010.12.015.

39. Peplonska B, Bukowska A, Sobala W. Rotating night shift work and physical activity of nurses and midwives in the cross-sectional study in Lodz, Poland. Chronobiol Int. 2014;31:1152-9. https://doi.org/10.3109/07420528.2014.95 7296.

40. Peplonska B, Burdelak W, Krysicka J, Bukowska A, Marcinkiewicz A, Sobala W, et al. Night shift work and modifiable lifestyle factors. Int J Occup Med Environ Health. 2014;27:693-706. https://doi.org/10.2478/s13382-0140298-0.

41. Chastin SF, Egerton T, Leask C, Stamatakis E. Meta-analysis of the relationship between breaks in sedentary behavior and cardiometabolic health. Obesity (Silver Spring). 2015;23:1800-10. https://doi.org/10.1002/oby.21180.

Received for publication: 7 August 2016 